\title{
NUMERICAL AND THEORETICAL STUDIES ON DOUBLE STEEL PLATE COMPO- SITE WALLS UNDER COMPRESSION AT LOW TEMPERATURES
}

\author{
Zhe Wang ${ }^{1}$, Jia-Bao Yan ${ }^{1,2, *}$ and Xue-Mei Liu ${ }^{3}$ \\ ${ }^{1}$ School of civil engineering, Tianjin University, Tianjin 300350, China \\ ${ }^{2}$ Key Laboratory of Coast Civil Structure Safety of Ministry of Education, Tianjin University, Tianjin 300350, China \\ ${ }^{3}$ Department of Infrastructure Engineering, The University of Melbourne, Parkville, VIC 3010, Australia \\ *(Corresponding author: E-mail: ceeyanj@163.com)
}

\section{A B S T RA C T}

Double steel plate composite walls (DSCWs) with several unique types of connectors have been implemented to protect offshore oil exploration platforms from concentric forces caused by ice in the Arctic region. This paper investigates the compressive performance of DSCWs with interlocked J-hooks and overlapped headed studs at low temperatures ranging from $20{ }^{\circ} \mathrm{C}$ to $-80^{\circ} \mathrm{C}$ with nonlinear finite element models (FEMs). The intricate geometric size of the concrete, multiple interactions of the concrete with the connectors, and material nonlinearities of the concrete have been thoroughly simulated. The reasonable consistency between the results of the monotonic tests and finite element analysis (FEA) on nine DSCWs with interlocked J-hooks and seven DSCWs with overlapped headed studs indicates that the FEMs can effectively predict the compressive performance of the DSCWs at low temperatures. On the basis of the validated FEMs, the effects of the horizontal and vertical spacing of the connectors on the compressive performance of the DSCWs are studied. Finally, theoretical models of the load-displacement curves are developed to reveal the compressive response of DSCWs at low temperatures with different types of connectors, taking into account the restraining effect of steel plates on the inner concrete and the local buckling of steel plates. Compared with previous tests and FEA, the developed theoretical models have reasonable consistency for the load-displacement curves of DSCWs at low temperatures.

\section{ART I C L E H I S T O R Y}

$\begin{array}{ll}\text { Received: } & \text { 27 June } 2020 \\ \text { Revised: } & \text { 31 January } 2021 \\ \text { Accepted: } & \text { 6 February 2021 }\end{array}$

\section{K E Y W O R D S}

Double steel plate composite

wall;

Low temperature;

Arctic protective structure;

Compressive performance;

Nonlinear finite element model;

Theoretical models

\section{Introduction}

Recently, the Arctic region has attracted strong interest from researchers because of its potential oil and gas resources [1]. The lowest temperature is approximately $-70{ }^{\circ} \mathrm{C}$ in the Arctic, introducing great challenges to infrastructure. Meanwhile, due to global warming, the rapid melting of ice is a matter of serious concern, increasing the concentration of floating ice in the Arctic. These ice sheets continuously impact oil and gas platforms. Under such fatigue impacts, the service life of such platforms is greatly reduced. Thus, it is necessary to propose a novel protective structure that can be applied to oil and gas platforms. Marshall et al. [2] and Yan et al. [3] developed a DSCW as a protective structure for Arctic offshore platforms, as demonstrated in Fig. 1. A DSCW consists of a sandwiched concrete core with two outer steel plates, which are integrally connected with mechanical shear connectors at the steel-concrete interface. Different types of connectors have been developed and employed in steel-concrete composite walls, e.g., J-hooks and headed studs. The DSCW exhibits superior properties compared to those of conventional reinforced concrete structures, e.g., reduced formwork, increased construction efficiency and high performance under static, seismic, blast and impact loads [4-6].

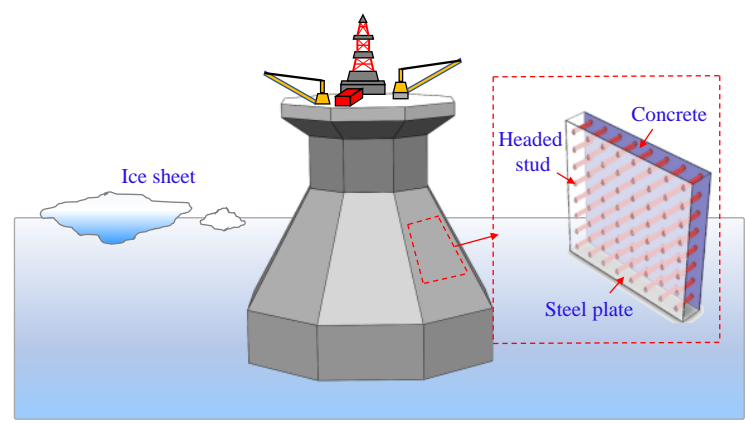

Fig. 1 Application of the DSCW in Arctic offshore platforms [9]

The compressive performance of DSCWs at low temperatures has been experimentally studied in Refs. [7-9]. However, these experimental studies proved to be costly and time consuming, and these tests have limitations in that the influences of the vertical and horizontal spacing of the connectors on the compressive performance of DSCWs at low temperatures have not been thoroughly researched. To overcome these limitations, finite element analysis (FEA) is an alternative way to study the compressive performance of DSCWs.

Several scholars have investigated the push-out behaviour of headed studs by FEM with only a few studs to obtain their shear strength [10-13]. However, for DSCWs with many studies, those models will experience nonconvergence problems [13-14]. Shanmugam et al. [15] proposed a simplified FEM of an SCS sandwich panel, in which the shear-slip behaviour of a head stud at the steelconcrete interface was simulated by a nonlinear spring. Yan et al. [16-17] simplified the interlocked J-hook and overlapped headed stud in the FEM of double steel plate composite structures to two cylindrical studs connected by a nonlinear spring element at its geometric centre. The reliability of the FEM was validated through the test results. Yan et al. [18] developed FEM that simplified the circle headed stud into square to predict the load-transferring mechanism and failure modes of the SCS sandwich plate. Qi et al. [19] investigated the tensile force and bending moment demands on headed studs in the design of DSCWs by FE method. The compressive local buckling behaviour of the steel plate in DSCWs was simulated by $\mathrm{Li}$ and $\mathrm{Hu}$ [20]. However, the concrete constitutive equation was simplified into a linear elasticity model and could not simulate the ultimate compressive bearing capacity of DSCWs. Fan et al. [21] established FEA modes on large-scale double steel plate composite structures, considering the details of connectors and local buckling of the steel plate. Vecchio and McQuade [22] treated the concrete and steel plate as one material, incorporated into the established 2D FE models of DSCWs. Although the peak loads predicted by the FEA were close to those of the test results, the FE models overestimated the lateral stiffness of the DSCW and failed to observe the local buckling of the steel plate.

Choi and Han [23] proposed calculation models for the initial stiffness and ductility coefficient of DSCWs. Based on Euler's formula, Zhang and Yang et al. [24-25] derived the calculation model of the compressive bearing capacity of steel plates considering the local buckling of the steel plate. Liang and Uy [26] developed two effective width formulas to calculate the maximum compressive capacity of short concrete-filled steel box columns, in which the length coefficient $\mathrm{K}$ was considered to be 0.7 by assuming that the boundary condition of the steel faceplate was a semi-fixed support. Yan et al. [27] recommended theoretical models to obtain the ultimate compressive bearing capacity of sandwiched concrete in DSCWs, which took into account the constraints of the steel plate working with overlapped headed studs on the sandwiched concrete. Yan et al. [28-29] proposed novel EC connectors incorporated into the DSCSWs and developed theoretical models to predict the ultimate compressive bearing capacity.

Based on recent studies, previous FE models and theoretical analysis have mainly focused on the compressive behaviours of DSCWs at ambient temperatures, and the theoretical model of the load-displacement curve of DSCWs at low temperatures has not been thoroughly studied. Thus, it is necessary to develop FE models and theoretical models to predict the 
compressive performance of DSCWs at low temperatures.

This paper develops FE models to study the compressive performance of DSCWs with J-hooks and headed studs at low temperatures. In these models, the connectors working in pairs are simulated by two cylindrical studs connected through a nonlinear spring element. The reasonable agreement of the ultimate compressive bearing capacity, load-displacement curves and failure modes between the results of the proposed FE analysis and several experimental investigations proves the accuracy of the FEM. With the affirmed FEM, parametric studies are accomplished to study the influence of the vertical and horizontal spacing of the connectors on the compressive performance of the DSCWs. Finally, on the basis of compressive tests and the FEA, theoretical models of load-displacement curves at low temperatures have been proposed to reveal the loading process.

\section{Axial compression tests on double steel plate composite walls [7-9]}

\subsection{Description of the specimens and materials}

The geometry of the DSCWs involved in the test program is shown in Fig. 2 , and they are composed of nine DSCWs with J-hooks and seven with headed studs. All specimens are composed of two external steel plates, studs (J-hooks or headed studs), sandwiched concrete, loading/end plates, and stiffeners.

Grade Q235 steel plates were used for all of the specimens, and the strength grade of the sandwiched concrete was C30, C40 and C50. J-hook connectors fabricated by grade HPB300 reinforcements were used for WJ1-WJ9. Meanwhile, headed studs with a diameter of $10 \mathrm{~mm}$ were used for WH1-WH7. More details of each specimen and the material properties are given in Table 1.

\subsection{Experimental setup}

A 1500-ton universal testing machine, as illustrated in Fig. 3, was used for the compression tests of DSCWs at low temperatures. Monotonic axial loading applied to the DSCWs was controlled by the displacement at a rate of 0.05 $\mathrm{mm} / \mathrm{min}$ during the tests.

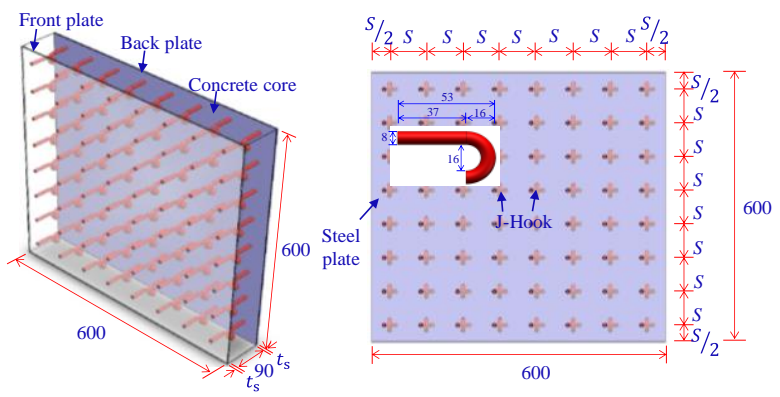

(a) Details of the DSCWs with J-hooks (WJ1-WJ9)

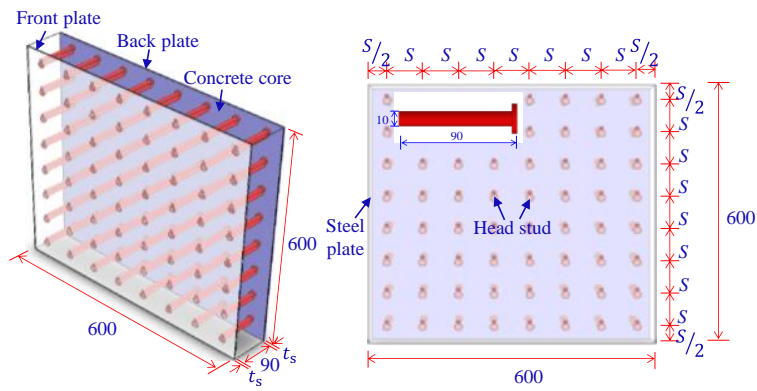

(b) Details of the DSCWs with headed studs (WH1-WH7)

Fig. 2 Details of the DSCWs (unit: mm) [7]

Table 1

Details of the double steel plate composite walls

\begin{tabular}{|c|c|c|c|c|c|c|c|c|c|c|}
\hline Item & $\begin{array}{c}T \\
\left({ }^{\circ} \mathrm{C}\right)\end{array}$ & $\begin{array}{c}t_{\mathrm{s}} \\
(\mathrm{mm})\end{array}$ & $\begin{array}{c}f_{\mathrm{y} T} \\
(\mathrm{MPa})\end{array}$ & $\begin{array}{c}E_{\mathrm{s} T} \\
(\mathrm{GPa})\end{array}$ & $\underset{(\mathrm{mm})}{S}$ & $S / t_{\mathrm{s}}$ & $\begin{array}{c}\sigma_{\mathrm{u} T} \\
(\mathrm{MPa})\end{array}$ & $\begin{array}{c}E_{\mathrm{sh} T} \\
(\mathrm{GPa})\end{array}$ & $\begin{array}{c}f_{\mathrm{c} T} \\
(\mathrm{MPa})\end{array}$ & $\begin{array}{c}E_{\mathrm{c} T} \\
(\mathrm{GPa})\end{array}$ \\
\hline & (1) & (2) & (3) & (4) & (5) & $(5) /(2)$ & (7) & (4) & (8) & (9) \\
\hline WJ1 & 20 & 2.8 & 334 & 201 & 75 & 26.8 & 330 & 199 & 43.9 & 28.4 \\
\hline WJ2 & -30 & 2.8 & 361 & 210 & 75 & 26.8 & 347 & 200 & 61.7 & 32.2 \\
\hline WJ3 & -60 & 2.8 & 378 & 216 & 75 & 26.8 & 353 & 204 & 75.6 & 33.1 \\
\hline WJ4 & -60 & 4.6 & 396 & 224 & 75 & 16.2 & 353 & 204 & 75.6 & 33.1 \\
\hline WJ5 & -60 & 5.9 & 401 & 226 & 75 & 12.6 & 353 & 204 & 75.6 & 33.1 \\
\hline WJ6 & -60 & 2.8 & 378 & 216 & 150 & 53.6 & 353 & 204 & 75.6 & 33.1 \\
\hline WJ7 & -60 & 2.8 & 378 & 216 & 75 & 26.8 & 353 & 204 & 48.2 & 32.8 \\
\hline WJ8 & -60 & 2.8 & 378 & 216 & 75 & 26.8 & 353 & 204 & 79.3 & 33.6 \\
\hline WJ9 & -80 & 2.8 & 391 & 222 & 75 & 26.8 & 360 & 206 & 87.0 & 34.6 \\
\hline WH1 & 20 & 2.8 & 334 & 201 & 75 & 26.8 & 494 & 198 & 43.9 & 28.4 \\
\hline WH2 & -30 & 2.8 & 361 & 210 & 75 & 26.8 & 522 & 198 & 61.7 & 32.2 \\
\hline WH3 & -60 & 2.8 & 378 & 216 & 75 & 26.8 & 555 & 205 & 75.6 & 33.1 \\
\hline WH4 & -60 & 4.6 & 396 & 224 & 75 & 16.2 & 555 & 205 & 75.6 & 33.1 \\
\hline WH5 & -60 & 5.9 & 401 & 226 & 75 & 12.6 & 555 & 205 & 75.6 & 33.1 \\
\hline WH6 & -60 & 2.8 & 378 & 216 & 150 & 53.6 & 555 & 205 & 75.6 & 33.1 \\
\hline WH7 & -80 & 2.8 & 391 & 222 & 75 & 26.8 & 593 & 204 & 87.0 & 34.6 \\
\hline
\end{tabular}

$T$ denotes the temperature; $t_{\mathrm{s}}$ denotes the thickness of the steel plate; $f_{\mathrm{y} T}$ and $E_{\mathrm{s} T}$ denote the yield strength and elastic modulus of the steel plate at low temperatures, respectively; $S$ denotes the spacing of the connectors; $\sigma_{\mathrm{u} T}$ and $E_{\mathrm{sh} T}$ denote the ultimate strength and elastic modulus of the connectors at low temperatures, respectively; and $f_{\mathrm{c} T}$ and $E_{\mathrm{c} T}$ denote the compressive strength and modulus of elasticity of the concrete at low temperatures, respectively.

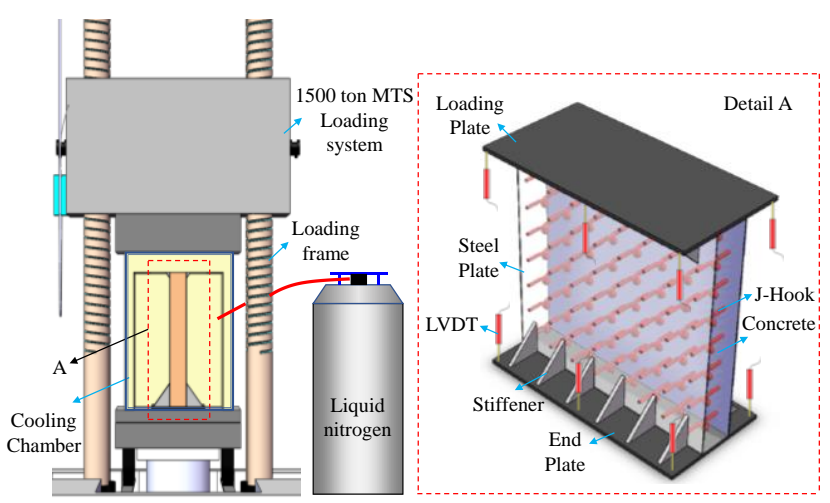

Fig. 3 Test setup of the DSCW
The compressive bearing capacity $P_{\mathrm{e}}$, vertical displacement $\Delta_{T}$ and strain of the steel plate $\varepsilon_{\mathrm{s} T}$ must be measured during the test process. The compressive bearing capacity was measured directly by the load cell in the testing machine. Eight linear voltage displacement transducers (LVDTs) were arranged at the corners of the loading/end plates to measure the vertical displacement of the DSCWs. Linear strain gauges were attached to the steel plates between two rows of studs to measure the buckling strain.

\section{Numerical analysis of the DSCWs}

\subsection{General}

The compressive performance of the DSCWs is simulated by the general finite element package ABAQUS [30], and the implicit solver is used for the analysis solutions. To improve the accuracy of the FEM, the different components of the DSCW reported in [7,8,9], e.g., sandwiched concrete, steel 
plate, loading/end plates and stiffeners, were modelled in detail. The geometric dimensions, mesh, material model, modelling of the connectors, steel-concrete interactions, loading and boundary conditions of the FEM are described in the following sections. It is worth noting that similar FEMs, established according to test parameters reported by Choi and Han [23], are also applied to FEA. More details of the FEMs can be found in Ref. [23,27].

\subsection{Geometric dimensions and mesh of the FEM}

Fig. 2 and Table 1 present the detailed geometric dimensions of the DSCWs reported in $[7,8,9]$, and the variables of the geometric dimensions include the steel plate thickness and connector space.

The FE model of the DSCW under compression is shown in Fig. 4. All of the components of the DSCW, including the concrete, steel plate, connectors, stiffeners and loading/end plates, are simulated by three-dimensional eight-node solid elements with a reduced integration point (C3D8R). Notably, the mesh size is critical to the accuracy of the FE analysis. A reasonable mesh size not only improves the accuracy of the FEA but also saves computing time. Due to the complex geometry of the FEM, each part is meshed and cut into regularly small pieces until all of the small pieces turn green. Considering the large stress level at the connectors, the mesh sizes of the concrete and steel plate around the connectors are encrypted within a reasonable range to improve the calculation accuracy of those areas. Taking specimen WJ1 as an example, there are 43,520 and 13,312 elements in the sandwiched concrete and steel plate with connectors, respectively.

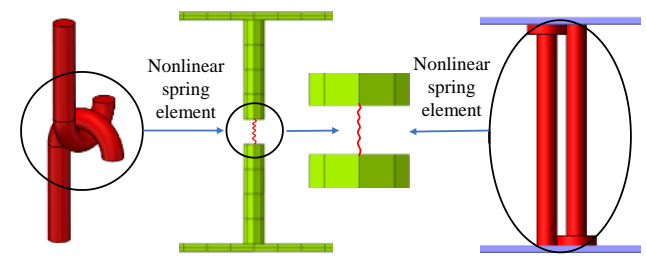

(a) Simulation of the stud connectors by the spring elemen

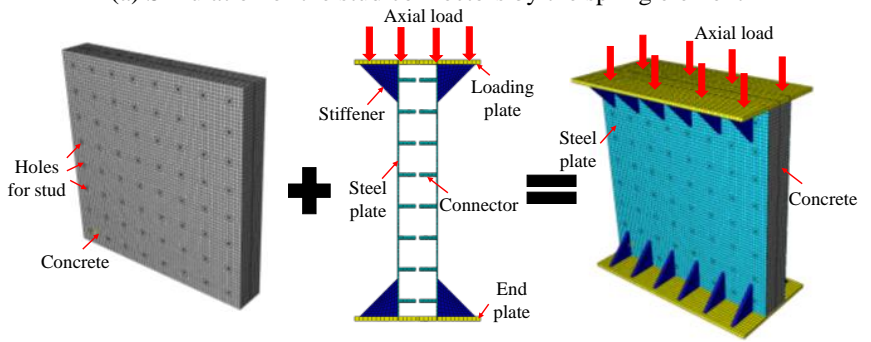

(b) Finite element model

Fig. 4 Finite element model of the DSCWs

\subsection{Materials model}

\subsubsection{Material model for concrete}

The concrete damage plasticity (CDP) model was applied to simulate the compressive performance of the sandwiched concrete in the DSCW at low temperatures, which could present two failure modes, namely, compressive crushing and tensile cracking, that may occur in sandwiched concrete during the loading process. To increase the reliability of the FEM, the compressive behaviour and tensile behaviour in the CDP model should be entered precisely.

The compressive constitutive equation of concrete recommended by Xie et al. [31] is used to express the elastic-plastic properties of concrete at low temperatures as given below:

$$
\sigma_{\mathrm{c} T}= \begin{cases}f_{\mathrm{c} T}\left[A \frac{\varepsilon_{\mathrm{c} T}}{\varepsilon_{0 T}}+(3-2 A)\left(\frac{\varepsilon_{\mathrm{c} T}}{\varepsilon_{0 T}}\right)^{2}+(A-2)\left(\frac{\varepsilon_{\mathrm{c} T}}{\varepsilon_{0 T}}\right)^{3}\right], 0 \leq \frac{\varepsilon_{\mathrm{c} T}}{\varepsilon_{0 T}} \leq 1 \\ f_{\mathrm{c} T} \frac{\varepsilon_{\mathrm{c} T}}{\varepsilon_{0 T}}\left[B\left(\frac{\varepsilon_{\mathrm{c} T}}{\varepsilon_{0 T}}-1\right)^{2}+\frac{\varepsilon_{\mathrm{c} T}}{\varepsilon_{0 T}}\right]^{-1}, & \frac{\varepsilon_{c T}}{\varepsilon_{0 T}}>1\end{cases}
$$

where $\sigma_{\mathrm{c} T}$ and $\varepsilon_{\mathrm{c} T}$ denote the concrete stress and strain under compression at temperature $T$, respectively, $f_{\mathrm{c} T}$ denotes the concrete strength under compression at temperature $T$, and $\varepsilon_{0 T}$ denotes the concrete strain under compression corresponding to $f_{\mathrm{c} T}$. The values of constants $A$ and $B$ are shown in Table 2.
Table 2

Coefficients $A$ and $B$ for concrete at different low temperatures

\begin{tabular}{ccccc}
\hline Coefficient & $20^{\circ} \mathrm{C}$ & $0^{\circ} \mathrm{C}$ & $-40^{\circ} \mathrm{C}$ & $-80^{\circ} \mathrm{C}$ \\
\hline$A$ & 2.7 & 2.7 & 2.2 & 1.8 \\
$B$ & 0.7 & 1.3 & 1.7 & 2.0 \\
\hline
\end{tabular}

The tensile behaviour of concrete is represented in this FEM by the fracture energy model, in which the parameter can be obtained as follows [33]:

$$
G_{f}=G_{f 0}\left(\frac{f_{\mathrm{ck}}}{10}\right)^{0.7}
$$

where $G_{f}$ denotes the fracture energy of concrete, $\mathrm{Nmm} / \mathrm{mm}^{2}$, and $f_{\mathrm{ck}}$ denotes the concrete cylinder strength under compression, MPa. According to the results of the material tests, $G_{f}=0.090 \mathrm{Nmm} / \mathrm{mm}^{2}$ was adopted in this FEM to describe the tensile behaviour.

Other plasticity parameters in the CDP model referring to the ABAQUS user manual [32], such as the dilation angle, eccentricity, $f_{\mathrm{b} 0} / f_{\mathrm{c} 0}, K$ and viscosity parameter, are $26^{\circ}, 0.1,1.16,0.667$ and 0.0001 , respectively.

\subsubsection{Material model for the steel plate and connectors}

Fig. 5 shows the elastic-plastic isotropic model employed to predict the material properties of the steel plate and connectors in the DSCW at low temperatures. There are two parts in this bi-linear material model, namely, the elastic part and plastic part. The elastic part is linear up to the yield strength for the steel plate and connectors, in which Young's modulus $E_{\mathrm{s} T}$ and Poisson's ratio $v$ need to be entered. Meanwhile, the plastic part is also linear up to the ultimate strength, in which the yield strength $f_{\mathrm{y} T}$, ultimate strength $f_{\mathrm{su} T}$ and the corresponding strain $\varepsilon_{\mathrm{su} T}$ should be precisely defined. The parameters mentioned above are all obtained through tests, as given in Table 1.

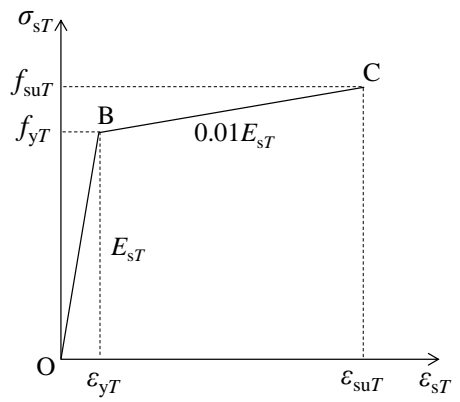

Fig. 5 Stress-strain curve of the steel used in the FEM

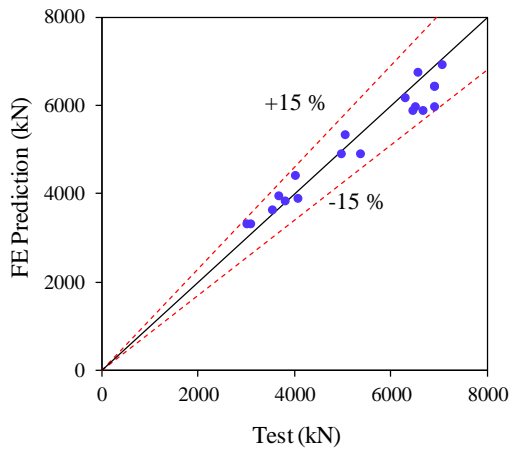

(a) Comparisons between the FE predictions and test results

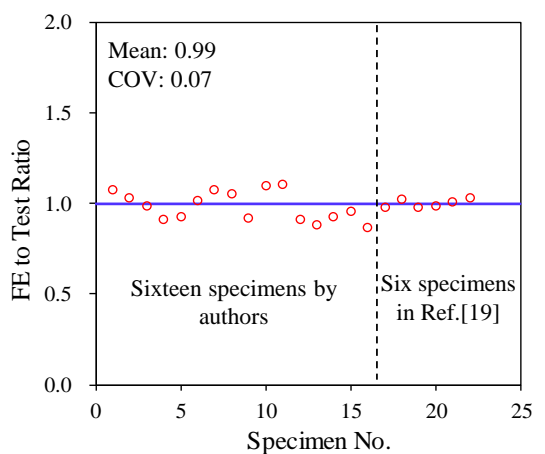

(b) Scatter of the FE-to-test ratios for $P_{\mathrm{u} T}$

Fig. 6 Comparisons of the FE predictions of the ultimate bearing capacity with the test values 


\subsection{Modelling of the connectors}

The interlocked J-hooks and overlapped headed studs in the DSCW must be simulated reasonably because the connectors, effectively maintaining the composite action of the steel plate and concrete, not only transfer the shear force at the contact between the steel plate and concrete but also prevent the premature local buckling of the steel plate. However, it is difficult to simulate the full geometry of the connectors due to the intricate geometry of the connectors themselves and the connector holes reserved in concrete, introducing great challenges to partitioning and producing the mesh while also causing nonconvergence of the FEM with the increasing number of elements. To solve the problems mentioned above, the geometry of the connectors is simplified into two cylinders with the same diameter as the connectors in the tests. One side of the cylinder merges with the steel plate into one part, and the other side of the two cylinders is connected by a three-dimensional spring element with nonlinear properties [16], as demonstrated in Fig. 4(a). The spring stiffness of $24,000 \mathrm{~N} / \mathrm{mm}$ obtained from pull-out tests $[16,34]$ needs to be properly defined. This simplified method for interlocked J-hooks or overlapped headed studs in steel-concrete composite structures is proven to be reasonable.

\subsection{Steel-concrete interactions, loading and boundary conditions}

This FEM adopted general contacts at all the surface pairs to simplify the model and save computing time. The contact properties of the tangential behaviour with a friction coefficient of 0.4 [35] and normal behaviour with a "hard" contact have been defined. Tie constraints were used among the steel plates, stiffeners and loading/end plates. A displacement load was applied axially at a reference point coupled to the loading plate, as shown in Fig. 4(b), and the end plate was restrained to move against all degrees of freedom.

Table 3

Comparisons of the ultimate compressive bearing capacity of the DSCWs

\begin{tabular}{|c|c|c|c|c|c|}
\hline Item & $\begin{array}{c}P_{\mathrm{e}} \\
(\mathrm{kN}) \\
(1)\end{array}$ & $\begin{array}{c}P_{\mathrm{f}} \\
(\mathrm{kN}) \\
(2)\end{array}$ & $\begin{array}{c}P_{\mathrm{t}} \\
(\mathrm{kN}) \\
(3)\end{array}$ & $\begin{array}{l}P_{\mathrm{f}} / P_{\mathrm{e}} \\
(2) /(1)\end{array}$ & $\begin{array}{l}P_{\mathrm{t}} / P_{\mathrm{e}} \\
(3) /(1)\end{array}$ \\
\hline & Tests by & Authors & & & \\
\hline WJ1 & 3062 & 3311 & 3510 & 1.08 & 1.15 \\
\hline WJ2 & 3532 & 3638 & 3782 & 1.03 & 1.07 \\
\hline WJ3 & 4968 & 4908 & 5338 & 0.99 & 1.07 \\
\hline WJ4 & 6442 & 5874 & 6403 & 0.91 & 0.99 \\
\hline WJ5 & 6897 & 6424 & 7074 & 0.93 & 1.03 \\
\hline WJ6 & 3783 & 3847 & 4456 & 1.02 & 1.18 \\
\hline WJ7 & 3654 & 3950 & 3831 & 1.08 & 1.05 \\
\hline WJ8 & 5046 & 5325 & 5540 & 1.06 & 1.10 \\
\hline WJ9 & 6508 & 5984 & 5999 & 0.92 & 0.92 \\
\hline WH1 & 3001 & 3310 & 3510 & 1.10 & 1.17 \\
\hline WH2 & 3991 & 4428 & 4540 & 1.11 & 1.14 \\
\hline WH3 & 5360 & 4908 & 5338 & 0.92 & 1.00 \\
\hline WH4 & 6658 & 5873 & 6403 & 0.88 & 0.96 \\
\hline WH5 & 6890 & 6424 & 7074 & 0.93 & 1.03 \\
\hline WH6 & 4062 & 3883 & 4456 & 0.96 & 1.10 \\
\hline \multirow[t]{2}{*}{ WH7 } & 6891 & 5976 & 5999 & 0.87 & 0.87 \\
\hline & Tests in & Ref. [23] & & & \\
\hline SS400-S & 6282 & 6175 & 6417 & 0.98 & 1.02 \\
\hline SM490-S & 6562 & 6749 & 7074 & 1.03 & 1.08 \\
\hline SS400-M & 7051 & 6934 & 7707 & 0.98 & 1.09 \\
\hline SM490-M & 8069 & 7946 & 7707 & 0.98 & 0.96 \\
\hline SS400-L & 8956 & 9032 & 9990 & 1.01 & 1.12 \\
\hline SM490-L & 8850 & 9156 & 9990 & 1.03 & 1.13 \\
\hline Mean & & & & 0.99 & 1.05 \\
\hline $\mathrm{Cov}$ & & & & 0.07 & 0.08 \\
\hline
\end{tabular}

$P_{\mathrm{e}}$ and $P_{\mathrm{t}}$ denote the experimental and theoretical ultimate compressive bearing capacity, respectively; $P_{\mathrm{f}}$ is the predicted ultimate compressive bearing capacity by the FEM.

\subsection{Validations and discussions}

The previous 16 compression tests on DSCWs reported in $[7,8,9]$ and 6 tests reported in $[23,27]$ were used to validate the ultimate compressive bearing capacity, load-displacement curves and failure modes of the developed FEM.

\subsubsection{Ultimate compressive bearing capacity}

Table 3 and Fig. 6 compare the predicted ultimate compressive bearing capacity by the FEA with the experimental values of the 16 DSCWs reported by the authors and 6 specimens reported by Choi and Han. It can be shown that the FE results achieve close agreement with the test results in terms of the ultimate compressive bearing capacity of the DSCW. The errors of the FE predicted values are within $\pm 15 \%$, and the average ratio of $P_{\mathrm{f}} / P_{\mathrm{e}}$ is 0.99 with a coefficient of variation (COV) of 0.07 .

\subsubsection{Load-displacement curves}

Fig. 7 compares the numerical load-displacement curves with the experimental curves obtained by the authors. These figures show that the numerical load-displacement curves divided into three stages, namely, the elastic stage, non-elastic stage, and recession stage, reasonably agree with the experimental curves except for the initial stiffness. The reasons for this difference may be as follows: (1) initial imperfections inside the specimens caused by welding the steel plates and connectors, pouring the concrete, and transporting the specimens; (2) non-axial compression due to the non-flatness of the loading/end plates; and (3) errors of the displacement measurement due to the complicated test process under low temperatures.

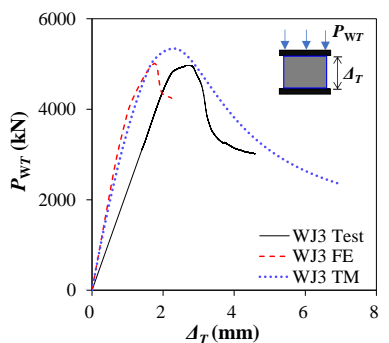

(a) $\mathrm{WJ} 3$

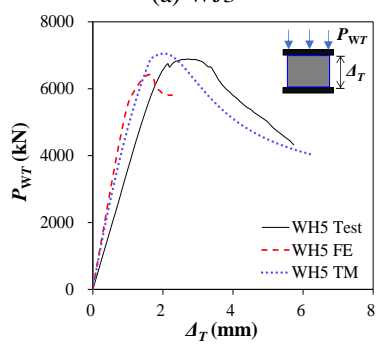

(c) WH5

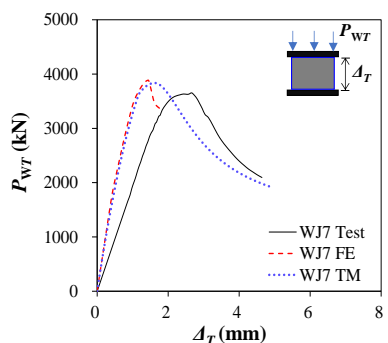

(b) WJ7

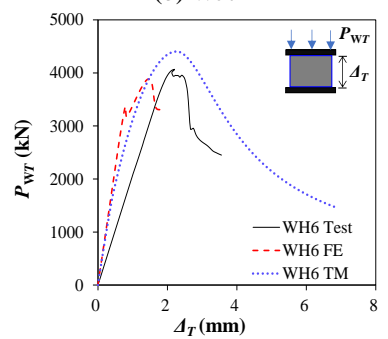

(d) WH6
Fig. 7 Validations of the load-displacement curves of the DSCWs by authors

Fig. 8 shows the comparisons of the load-displacement curves between the FE predictions and the experimental curves obtained from the tests in Ref. [23]. If the tests can eliminate the disadvantages mentioned above, the loaddisplacement curves will be perfectly predicted by the FEA, including the initial stiffness.

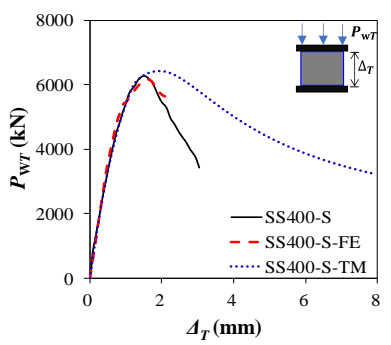

(a) $\mathrm{SS} 400-\mathrm{S}$

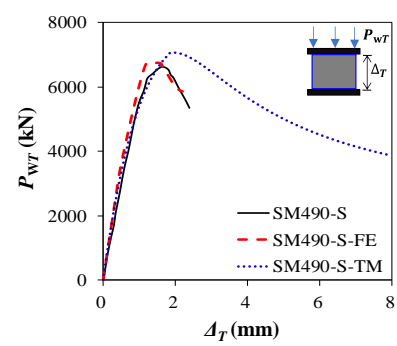

(b) SM490-S 


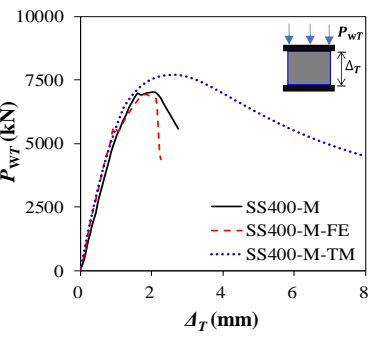

(c) SS400-M

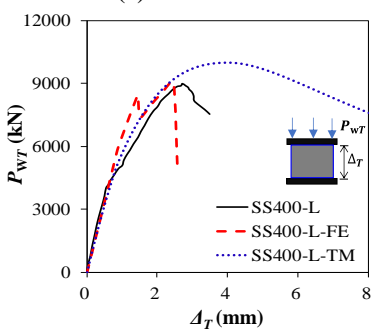

(e) SS400-L

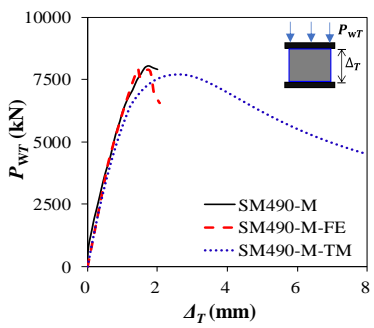

(d) SM490-M

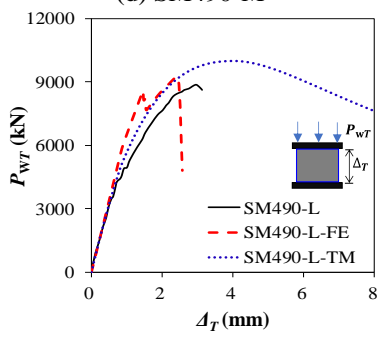

(f) SM490-L
Fig. 8 Validations of the load-displacement curves in Ref. [23]

\subsubsection{Failure modes}

Crushing and splitting of the concrete and local buckling of the steel plate occurred in the DSCWs under compression. Fig. 9 presents the failure mode comparisons between those observed from the tests and those predicted from the FEA, in which reasonable agreement was achieved.
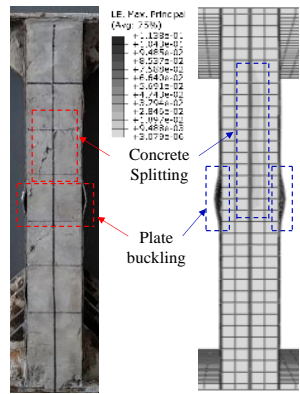

(a) $\mathrm{WJ} 2$

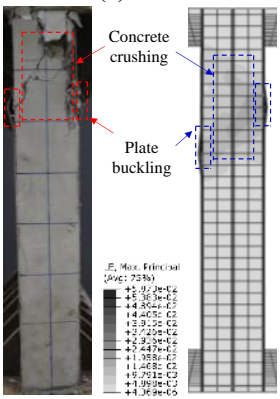

(c) WH3
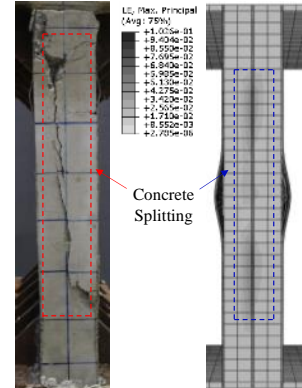

(b) WJ8

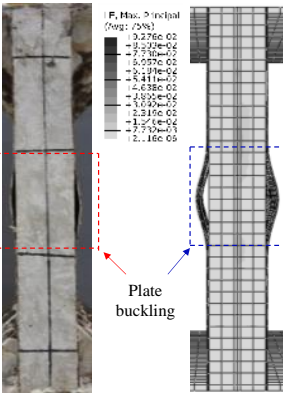

(d) WH6
Fig. 9 Validations of the failure modes of the FE modes with those of the experimental results

Through the above validations of the ultimate compressive bearing capacity, load-displacement curves, and failure modes, it can be proven that the FEM established in this study can properly simulate the compression performance of DSCWs.

\subsection{Parametric study}

Earlier experimental investigations have demonstrated the effects of the steel plate thickness, concrete strength, temperature, connector spacing and connector type on the compression performance of DSCWs. However, the influence of the vertical spacing $\left(S_{\mathrm{V}}\right)$ and horizontal spacing $\left(S_{\mathrm{H}}\right)$ of the connectors on the compression performance of DSCWs has not been fully investigated due to time and economic limitations. Thus, the FEM proposed in this paper can be used to conduct a parametric study, and only half of the DSCW is built to improve the efficiency of the FEA. The material properties of the models used for parametric analysis are the same as those of $\mathrm{WJ} 3$

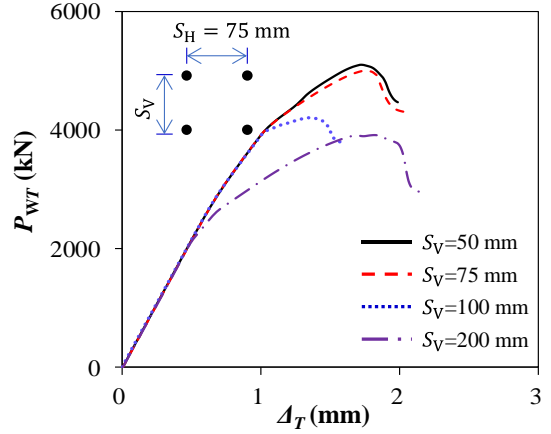

(a) $S_{\mathrm{H}}=75 \mathrm{~mm}$

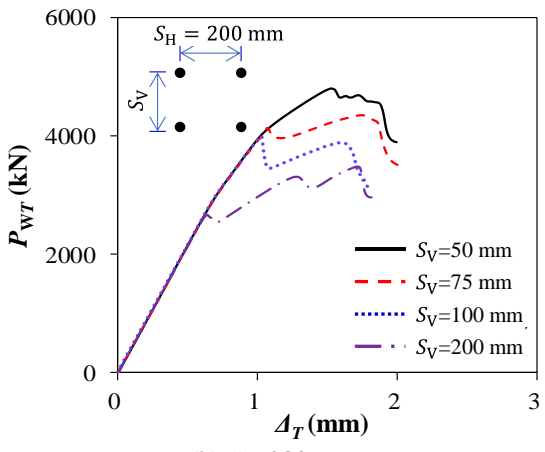

(b) $S_{\mathrm{H}}=200 \mathrm{~mm}$

Fig. 10 Influence of the vertical spacing of connectors on the $P_{\mathrm{W} T}-\Delta_{T}$ curve

\subsubsection{Influence of the vertical spacing of the connectors}

Fig. 10 demonstrates the impact of the vertical spacing of the connector on the compressive performance of the DSCWs when the horizontal spacing is $75 \mathrm{~mm}$ and $200 \mathrm{~mm}$. The steel plate and concrete are co-deformed at the initial loading stage with few interactions, causing the initial stiffness of the DSCWs, which is provided by the steel plate and concrete, to have a marginal influence with the increasing $S_{\mathrm{V}}$ value.

Fig. 11 presents the influence of the vertical spacing of the connectors on the area of local buckling of the steel plate when the DSCW reaches $P_{\mathrm{u} T}$. The area of local buckling of the steel plate, mainly observed between the horizontal rows of the connectors, rises with increasing values of $S_{\mathrm{V}}$. The larger the vertical spacing of the connectors is, the less the vertical constraint of the steel plate, which ultimately increases the area of local buckling of the steel plate.

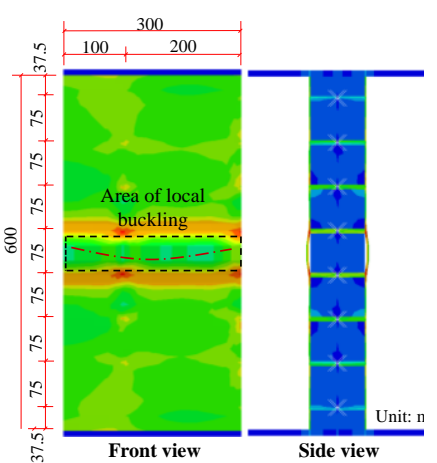

(a) $S_{\mathrm{V}}=75 \mathrm{~mm}, S_{\mathrm{H}}=200 \mathrm{~mm}$

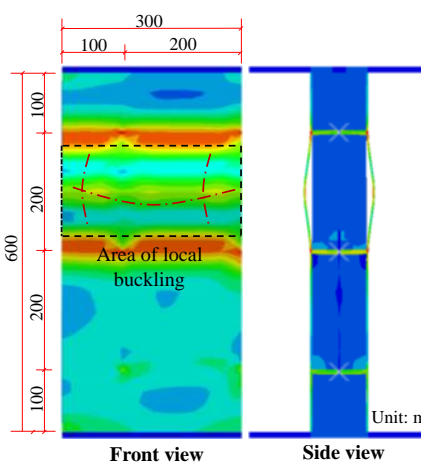

(b) $S_{\mathrm{V}}=200 \mathrm{~mm}, S_{\mathrm{H}}=200 \mathrm{~mm}$
Fig. 11 Influence of the vertical spacing of connectors on the area of local buckling of the steel plate

Fig. 12 illustrates the effect of the vertical spacing of the connectors on $P_{\mathrm{u} T}$ and $D I$. With increasing $S_{\mathrm{V}}$ values from 50 to 75,100 and $200 \mathrm{~mm}$, the $P_{\mathrm{u} T}$ (or $D I$ ) of the DSCW decreased by $2 \%$ (or $10 \%$ ), $17 \%$ (or $12 \%$ ) and $23 \%$ (or $19 \%$ ), respectively, when the horizontal spacing of the connectors $S_{\mathrm{H}}$ was $75 \mathrm{~mm}$, as shown in Fig. 12(a). Meanwhile, the $P_{\mathrm{u} T}$ (or DI) of the DSCW with a $S_{\mathrm{H}}$ of 200 $\mathrm{mm}$ declined by $9 \%$ (or $13 \%$ ), $17 \%$ (or $15 \%$ ) and $27 \%$ (or $16 \%$ ), respectively, as shown in Fig. 12(b). As the $S_{\mathrm{V}}$ value increases, the slenderness ratio $\left(S_{\mathrm{V}} / t_{\mathrm{s}}\right)$ of the steel plate increases from 16.7 to $25,33.3$ and 66.7. The higher slenderness ratio substantially decreased the buckling resistance of the steel plate under compression and accelerated the premature local buckling of the steel plate, adversely affecting the ductility of the DSCW. 


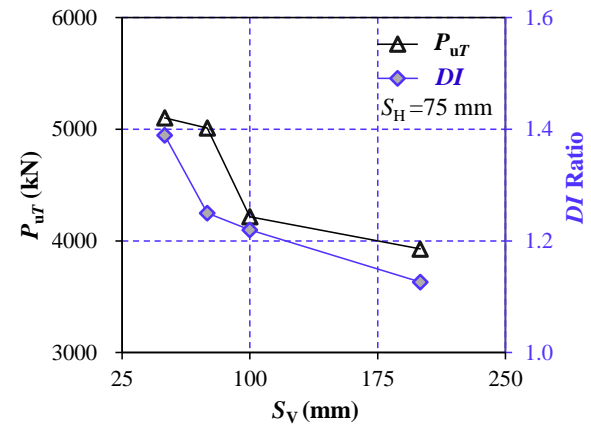

(a) $S_{\mathrm{H}}=75 \mathrm{~mm}$

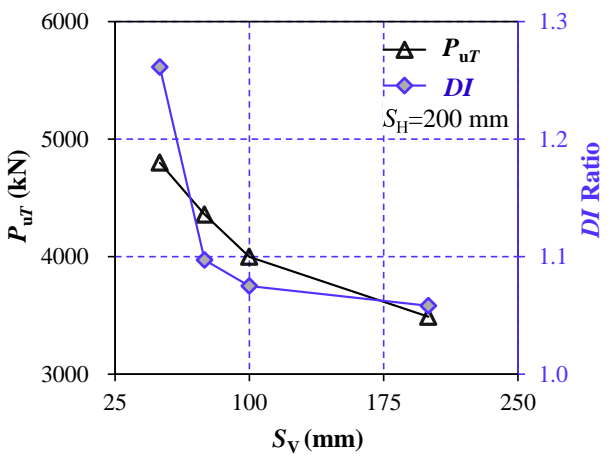

(b) $S_{\mathrm{H}}=200 \mathrm{~mm}$

Fig. 12 Influence of the vertical spacing of connectors on $P_{\mathrm{u} T}$ and $D I$

3.7.2. Influence of the horizontal spacing of the connectors

Fig. 13 indicates the effect of the horizontal spacing of the connectors on the compressive performance of the DSCWs. The value of $S_{\mathrm{H}}$ has little effect on the initial stiffness of the DSCW because of the co-deformation of the steel plate and concrete at the initial load with few interactions.

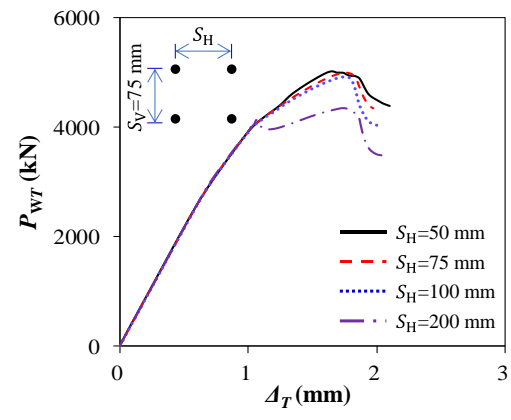

(a) $S_{\mathrm{v}}=75 \mathrm{~mm}$

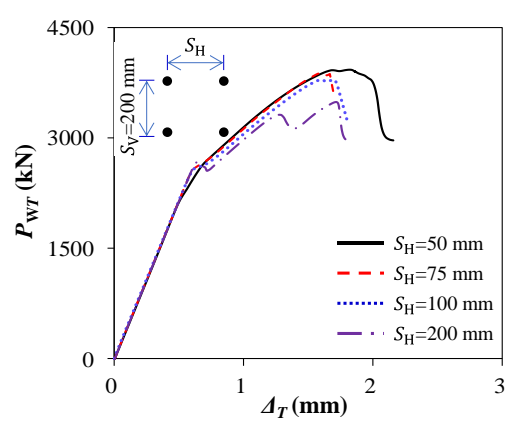

(b) $S_{\mathrm{V}}=200 \mathrm{~mm}$

Fig. 13 Influence of the horizontal spacing of connectors on the $P_{\mathrm{W} T-\Delta T}$ curve

Fig. 14 depicts the effect of the horizontal spacing of the connectors on the area of local buckling of the steel plate when the DSCW reaches $P_{\mathrm{u} T}$. As the value of $S_{\mathrm{H}}$ changes from $75 \mathrm{~mm}$ to $200 \mathrm{~mm}$, the area of local buckling increases slightly. Since the local buckling of the steel plate mainly appears between the horizontal rows of the connectors, the changes in $S_{\mathrm{H}}$ rarely affect the area of local buckling of the steel plate. However, the insufficient horizontal constraint caused by the increased value of $S_{\mathrm{H}}$ causes the local buckling of the steel plate to expand towards the adjacent row of connectors, which results in a slight increase in the area of local buckling of the steel plate.

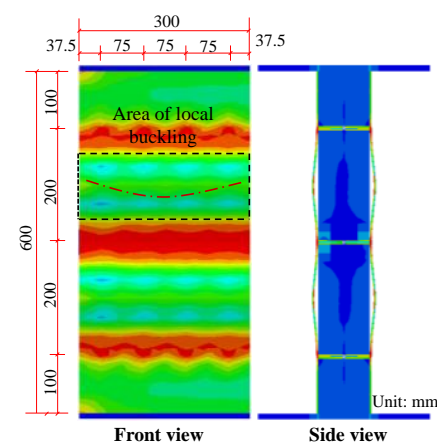

(a) $S_{\mathrm{V}}=200 \mathrm{~mm}, S_{\mathrm{H}}=75 \mathrm{~mm}$

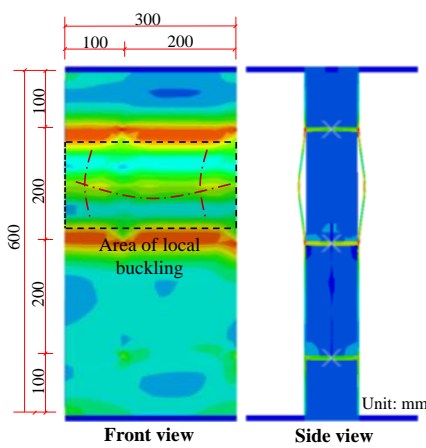

(b) $S_{\mathrm{V}}=200 \mathrm{~mm}, S_{\mathrm{H}}=200 \mathrm{~mm}$
Fig. 14 Influence of the horizontal spacing of connectors on the area of local buckling of the steel plate

Fig. 15 demonstrates the influence of $S_{\mathrm{H}}$ on $P_{\mathrm{u} T}$ and $D I$. Increasing the value of $S_{\mathrm{H}}$ from 50 to 75,100 and $200 \mathrm{~mm}$ decreases $P_{\mathrm{uT}}$ (or $D I$ ) by $1 \%$ (or $13 \%$ ), $2 \%$ (or $21 \%$ ) and $13 \%$ (or $24 \%$ ), respectively, when $S_{\mathrm{V}}$ is $75 \mathrm{~mm}$, as shown in Fig. 15(a). Meanwhile, the value of $P_{\mathrm{u} T}$ (or $D I$ ) of the DSCW with a $S_{\mathrm{V}}$ of $200 \mathrm{~mm}$ decreases by $1 \%$ (or $4 \%$ ), $3 \%$ (or $5 \%$ ) and $11 \%$ (or 6\%), respectively, as shown in Fig. 15(b). The increased $S_{\mathrm{H}}$ value with insufficient horizontal constraint on the steel plate and concrete accelerates the failure of the DSCW, which directly leads to the decreases in the $P_{\mathrm{u} T}$ and $D I$. However, it is worth noting that when the $S_{\mathrm{H}}$ value is less than $100 \mathrm{~mm}, S_{\mathrm{H}}$ has a greater influence on $D I$ than on $P_{\mathrm{u} T}$. In contrast, when $S_{\mathrm{H}}$ is greater than $100 \mathrm{~mm}, S_{\mathrm{H}}$ has a greater influence on $P_{\mathrm{u} T}$ than on $D I$. Thus, there must be a critical value for $S_{\mathrm{H}}$, which is worthy of further research in the future.

\section{Theoretical analysis of the compressive performance of the DSCW}

\subsection{Theoretical model}

The load-displacement curves obtained by the experimental studies indicate that the DSCW undergoes a total of three stages from loading to destruction. However, the previous theoretical models only predict the ultimate compressive bearing capacity of the DSCW without describing the loading process, which cannot reveal the failure mechanism of the composite structures. Thus, this study aims to incorporate the loading process in the theoretical model, namely, proposing a theoretical model for the load-displacement curve of the DSCW.

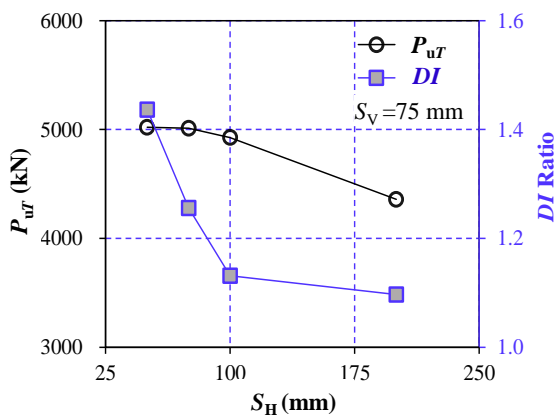

(a) $S_{\mathrm{V}}=75 \mathrm{~mm}$

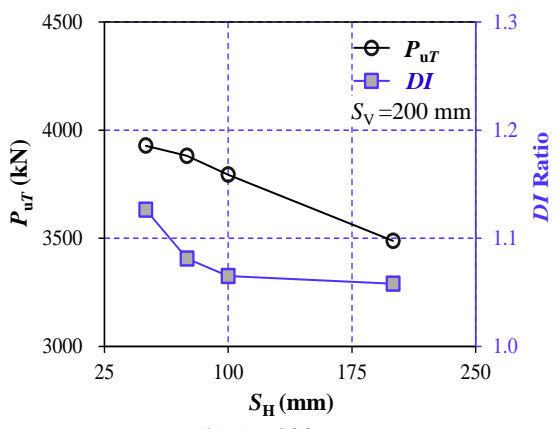

(b) $S_{\mathrm{V}}=200 \mathrm{~mm}$

Fig. 15 Influence of the horizontal spacing of connectors on the $P_{\mathrm{u} T}$ and $D I$

The theoretical model presented in this study takes into account the following assumptions:

(1) The compressive bearing capacity of the DSCW, $P_{\mathrm{WT}}$, is composed of the compressive bearing capacity of the sandwiched concrete, $P_{\mathrm{c} T}$, and the compressive bearing capacity of the steel plates, $P_{\mathrm{s} T}$ : 


$$
P_{\mathrm{w} T}=P_{\mathrm{c} T}+P_{\mathrm{s} T}
$$

(2) The sandwiched concrete and steel plates in the DSCW are co-deformed under compression, and the strains of the steel plate and concrete can be expressed as follows:

$$
\varepsilon_{\mathrm{c} T}=\varepsilon_{\mathrm{s} T}=\Delta_{T} / H
$$

where $\varepsilon_{\mathrm{c} T}$ and $\varepsilon_{\mathrm{s} T}$ denote the strain of the concrete and steel plate; $\Delta_{T}$ denotes the vertical displacement of the DSCW; and $H$ denotes the height of the DSCW.

\subsubsection{Theoretical model of the sandwiched concrete}

The sandwiched concrete is compressed biaxially under the constraint of the steel plate, which substantially improves the compressive bearing capacity of the concrete. Therefore, a strength improvement coefficient, $\alpha$, is introduced into the theoretical model of concrete as follows:

$$
P_{\mathrm{c} T}=\alpha \mathrm{g} \sigma_{\mathrm{cT}} A_{\mathrm{c}}
$$

where $\sigma_{\mathrm{c} T}$ denotes the concrete stress under compression, which can adopt the constitutive equation proposed by Xie et al. [31], as shown in Eq. (1); $A_{c}$ denotes the concrete cross-sectional area, $A_{\mathrm{c}}=W^{*} t_{\mathrm{c}}$; and $W$ and $t_{\mathrm{c}}$ are the width and thickness of the concrete, respectively. The strength improvement coefficient, $\alpha$, can be expressed as follows:

$$
\alpha=\frac{\sigma_{\mathrm{cc} T}}{f_{\mathrm{c} T}}
$$

where $\sigma_{\mathrm{cc} T}$ denotes the compressive strength of concrete under biaxial compression and $f_{\mathrm{c} T}$ denotes the concrete strength under uniaxial compression.

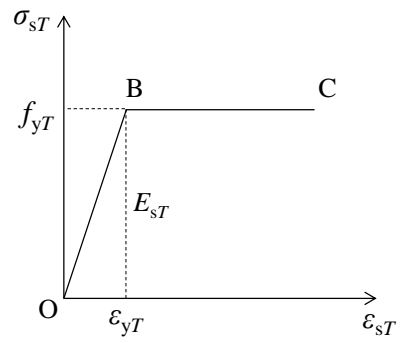

(a) $S / t_{s} \leq \eta$

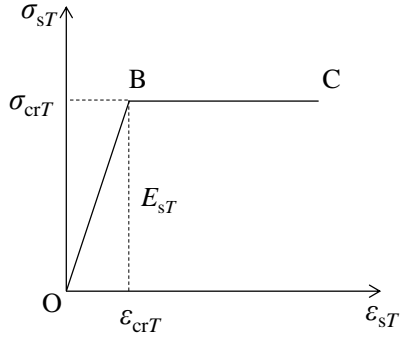

(b) $S / t_{\mathrm{s}}>\eta$
Fig. 16 The constitutive equation of the steel plate

The formulas recommended by Yan et al. [27] are used to calculate $\sigma_{\mathrm{cc} T}$ as given below:

$$
\sigma_{\mathrm{cc} T}=\frac{\lambda+\sqrt{\lambda^{2}-4\left(1-\alpha_{\mathrm{s}}^{2}\right)\left\{\sigma_{\mathrm{h}}^{2}-\left[\left(1-\alpha_{\mathrm{s}}\right) f_{\mathrm{cT}}+\alpha_{\mathrm{s}} \sigma_{\mathrm{h}}\right]^{2}\right\}}}{2\left(1-\alpha_{\mathrm{s}}^{2}\right)}
$$

$\lambda=\left(1+2 \alpha_{\mathrm{s}}^{2}\right) \sigma_{\mathrm{h}}+2\left(1-\alpha_{\mathrm{s}}\right) \alpha_{\mathrm{s}} f_{\mathrm{c} T}$

$$
\sigma_{\mathrm{h}}=\frac{T_{\mathrm{H}}}{S_{\mathrm{H}} S_{\mathrm{V}}}
$$

$$
T_{\mathrm{H}}=\left\{\begin{array}{l}
T_{\mathrm{s}}=A_{\mathrm{sd}} \sigma_{\mathrm{u} T} / \gamma_{\mathrm{M} 2} \\
T_{\mathrm{pl}}= \begin{cases}\left(0.9 f_{\mathrm{ck} T} e_{\mathrm{h}} d+0.116 \sigma_{\mathrm{y} T} d^{2}\right) / \gamma_{\mathrm{c}}, & \text { for J-hook } \\
8 A_{\mathrm{brg}} f_{\mathrm{cT} T} A_{\mathrm{N}} / \gamma_{\mathrm{c}} & , \text { for Headed stud }\end{cases} \\
T_{\mathrm{CB}}=0.333 \sqrt{f_{\mathrm{c} T}} A_{\mathrm{N}} / \gamma_{\mathrm{c}} \\
T_{\mathrm{ps}}=\pi d t_{\mathrm{s}}\left(f_{\mathrm{ys} T} / \sqrt{3}\right) / \gamma_{\mathrm{M} 0}
\end{array}\right\}
$$

where $\alpha_{\mathrm{s}}$ denotes the coefficient of shear yielding and is herein adopted as
$0.19 ; \sigma_{\mathrm{h}}$ represents the constrained stress contributed by the steel plate; $T_{\mathrm{H}}$ represents the resistance of the connectors under tensile forces; $A_{\text {sd }}$ represents the cross-sectional area of the connectors; $\sigma_{\mathrm{u} T}$ represents the ultimate tensile strength of the connectors; $A_{\text {brg }}$ represents the tensile area of the connectors; $d$ represents the diameter of the connectors; $e_{\mathrm{h}}$ is the anchoring length of the $\mathrm{J}$ hook; $A_{\mathrm{N}}$ represents the projection area of the concrete cone; $t_{\mathrm{s}}$ represents the thickness of the steel plate; and $\gamma_{\mathrm{M} 2}, \gamma_{\mathrm{c}}$ and $\gamma_{\mathrm{M} 0}$ are partial factors and are herein equal to 1.0 for prediction purposes.

\subsubsection{Theoretical model of the steel plate}

The compressive bearing capacity of the steel plate can be obtained by the following:

$$
P_{\mathrm{s} T}=2 \sigma_{\mathrm{s} T} A_{\mathrm{s}}
$$

where $\sigma_{\mathrm{s} T}$ denotes the steel plate stress under compression; $A_{\mathrm{s}}$ denotes the steel plate cross-sectional area, $A_{\mathrm{s}}=W^{*} t_{\mathrm{s}}$; and $W$ and $t_{\mathrm{s}}$ are the width and thickness of the steel plate, respectively. Two failure modes of the steel plate determined by the spacing-to-thickness ratio $\left(S_{\mathrm{v}} / t_{\mathrm{s}}\right)$ are observed in the DSCW [7], namely, buckling failure and yield failure. When $S_{\mathrm{V}} / t_{\mathrm{s}}$ is less than the critical value, $\eta$, the steel plate undergoes yield failure where the steel plate yields and then buckles with the constitutive equation given in Fig. 16(a). In contrast, when $S_{\mathrm{V}} / t_{\mathrm{s}}$ is greater than the critical value, $\eta$, the steel plate undergoes buckling failure where the steel plate buckles and then yields with the constitutive equation shown in Fig. 16(b). Therefore, the steel plate compressive stress can be determined as follows:

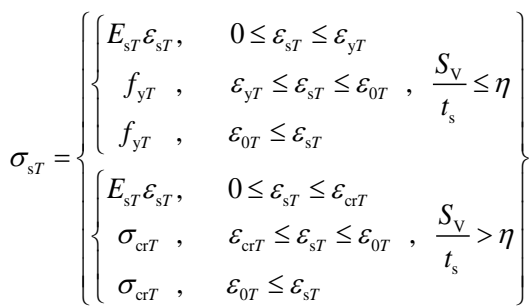

where $\sigma_{\mathrm{s} T}$ and $\varepsilon_{\mathrm{s} T}$ denote the compressive stress and strain of the steel plate; $\sigma_{\mathrm{cr} T}$ and $\varepsilon_{\mathrm{cr} T}$ denote the buckling stress and strain of the steel plate; $E_{\mathrm{s} T}$ is the steel plate elastic modulus; $f_{\mathrm{y} T}$ and $\varepsilon_{\mathrm{y} T}$ represent the steel plate yield stress and strain; $\varepsilon_{0 T}$ is the peak strain of the concrete under compression; and $\eta$ denotes the critical value of $S_{\mathrm{V}} / t_{\mathrm{s}}$.

The local buckling of the steel plate between the horizontal rows of connectors is observed according to the test results. Thus, the steel plate is simplified as a slender rod with the support points contributed by the connectors, as given in Fig. 17. Combined with the Euler formula [4,20], $\sigma_{\mathrm{cr} T}$ can be expressed as follows:

$$
\sigma_{\mathrm{cr} T}=\frac{\pi^{2} E_{\mathrm{s} T}}{12 K^{2}\left(S_{\mathrm{V}} / t_{\mathrm{s}}\right)^{2}}
$$

$$
\varepsilon_{\mathrm{cr} T}=\frac{\pi^{2}}{12 K^{2}\left(S_{\mathrm{V}} / t_{\mathrm{s}}\right)^{2}}
$$

$\eta=\sqrt{\frac{\pi^{2} E_{\mathrm{s} T}}{12 K^{2} f_{\mathrm{y} T}}}$

where $K$ denotes the effective length coefficient for local buckling and is herein equal to 0.825 according to the regression analysis by Yan [7].
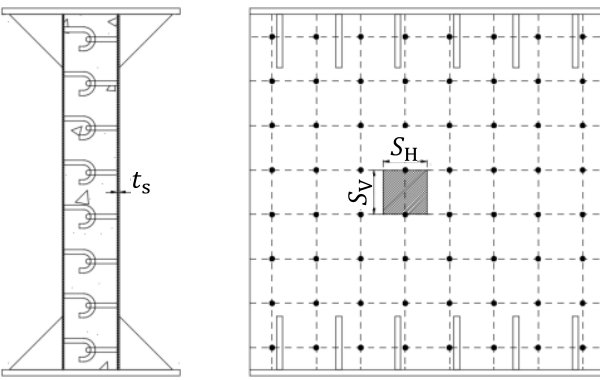

Fig. 17 Analysis model of local buckling 


\subsection{Validations}

Twenty-two compression tests on DSCWs $[7,8,9,23]$ have been analysed to validate the theoretical model proposed in this study. The validations comprise the ultimate compressive bearing capacity and load-displacement curves.

The experimental ultimate compressive bearing capacity of the DSCWs is compared with the predicted values by theoretical analysis, as shown in Table 3 and Fig. 18. The errors of the theoretical model predicted values are within $\pm 15 \%$. The average ratio of $P_{\mathrm{t}} / P_{\mathrm{e}}$ is 1.05 , and the coefficient of variation (COV) is 0.08 .

Fig. 7 compares the experimental load-displacement curves reported by the authors with those obtained from the numerical and theoretical studies. The results indicate that the degree of agreement of the load-displacement curves between the theoretical model and FEM is better than that between the theoretical model and tests. Meanwhile, the elastic stiffness of the loaddisplacement curves predicted by the theoretical model is greater than that in the experimental load-displacement curves. This discrepancy may be attributed to the initial imperfections, welding quality, residual stress, accidental eccentricities, and non-uniform axial loading. Fig. 8 shows the validations of the load-displacement curves reported by Choi and Han [23]. The loaddisplacement curves predicted by the theoretical analysis are in good agreement with the results from the tests and FEA.

All of the validations prove that the developed theoretical model can be used to predict the loading process of the DSCWs under compression. However, according to the Chinese code GB5011-2010 [35], the concrete grade in shear wall cannot exceed C60 to prevent brittle failure. Meanwhile, to improve utilization of steel plate, the steel plate should yield before the concrete crushed, namely $\varepsilon_{\mathrm{y} T}=f_{\mathrm{y} T} t E_{\mathrm{s} T} \leq \varepsilon_{\mathrm{o}} \mathrm{T}$. The peak strain $\left(\varepsilon_{\mathrm{oT}}\right)$ of normal weight concrete $(\mathrm{C} 20 \sim \mathrm{C} 60)$ is about 0.002 and the elastic modulus $\left(E_{\mathrm{s} T}\right)$ of steel plate is about $200 \mathrm{GPa}$. Thus, the yield strength $\left(f_{\mathrm{yT}}\right)$ of steel plate should not exceed $400 \mathrm{MPa}$. In addition, these formulae were only developed based on limited data, and only applicable to DSCWs with an aspect ratio of 1 within temperature interval of $\left[20^{\circ} \mathrm{C},-80^{\circ} \mathrm{C}\right]$

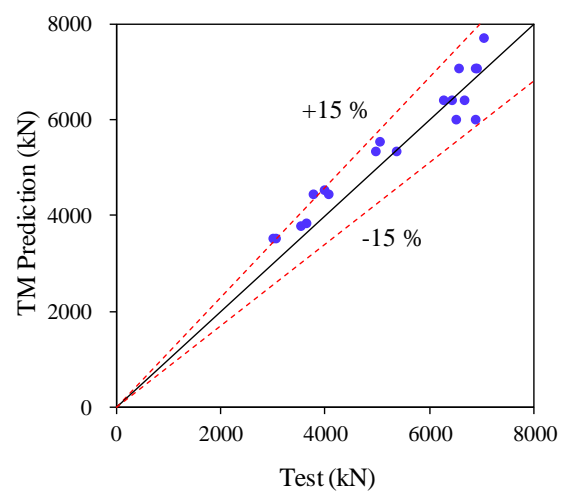

(a) Comparisons between the TM prediction and test results

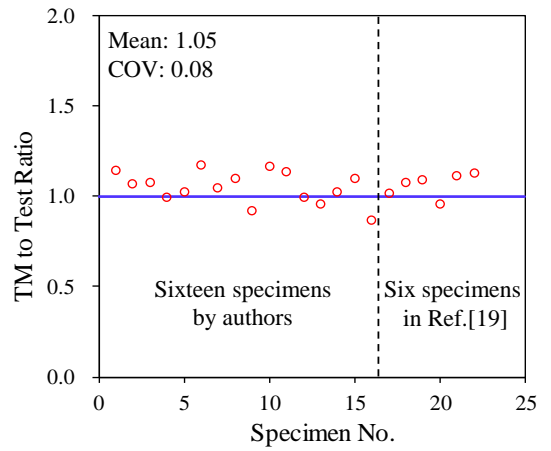

(b) Scatter of the TM to test ratios for $P_{\mathrm{u} T}$

Fig. 18 Comparisons of the TM predictions of the ultimate bearing capacity with the test values

\subsection{Steps for predicting the load-displacement curves of the DSCWs}

Step I: Use Eqs. (6)-(10) to determine the strength improvement coefficient of the sandwiched concrete provided by the steel plates and connectors;

Step II: Using Eqs. (1) and (5) to determine the load-strain curve of sandwiched concrete;

Step III: Use Eqs. (12)-(15) to determine the stress-strain curve of the steel plate which consider local buckling. Use Eq. (11) to determine the load-strain curve of the steel plate;

Step IV: Use Eqs. (3)-(4) to determine the load-displacement curve of the DSCW from loading to destruction.

\section{Conclusions}

This paper develops an FEM and a theoretical model to predict the compression performance of DSCWs with interlocked J-hooks and overlapped headed studs at low temperatures.

The validation results for the ultimate compressive bearing capacity, loaddisplacement curves, and failure modes of the DSCWs obtained from the experimental investigation and FEA prove that the FEM established in this study can reasonably predict the compression performance of DSCWs at low temperatures. On the basis of the validated FEM, the influence of the vertical and horizontal spacing of the connectors on the compressive performance of the DSCWs is studied. Both the vertical and horizontal spacing of the connectors have a minimal effect on the initial stiffness of the DSCWs. However, increasing vertical and horizontal spacing substantially decreases the ultimate compressive bearing capacity and ductility of the DSCWs.

Based on the experimental and numerical investigation, the theoretical model of the load-displacement curve is developed, considering the constraint of the steel plates on the sandwiched concrete and the local buckling of the steel plate. By comparing the load-displacement curves predicted by the theoretical model with the curves obtained from the tests, it can be shown that the predicted curves are also divided into three stages, namely, the elastic stage, non-elastic stage and recession stage, which indicates that the proposed theoretical model can reasonably predict the loading process of the DSCWs at low temperatures.

\section{Acknowledgment}

The authors would like to acknowledge the research grant 52178494 received from National Natural Science Foundation of China for the works reported herein. The authors gratefully express their gratitude for the financial supports.

\section{References}

[1] Gautier, D.L., Bird, K.J., Charpentier, R.R., Grantz, A., Houseknecht, D.H., Klett, T.R., et al. "Assessment of undiscovered oil and gas in the Arctic", Science, 324, 1175-1179, 2009. https://doi.org/10.1126/science.1169467.

[2] Marshall, P.W., Sohel, K.M.A., Liew, J.Y.R., Yan, J.B., Palmer, A., Choo, Y.S., "Development of SCS sandwich composite shell for arctic caissons", Offshore Technology Conference, paper no. 23818, Houston, Texas, USA, 2012. http://dx.doi.org/10.4043/23818MS.

[3] Yan, J.B., Liu, X.M., Liew, J.Y.R., Qian, X.D., Zhang, M.H., "Steel-concrete-steel sandwich system in Arctic offshore structures: materials, experiments, and design", Materials and Design, 91, 111-121,2016. https://doi.org/10.1016/j.matdes.2015.11.084.

[4] Sohel, K.M.A. and Liew, J.Y.R., "Behavior of steel-concrete-steel sandwich slabs subject to impact load", Journal of Constructional Steel Research, 100, 163-175, 2014 https://doi.org/10.1016/j.jcsr.2014.04.018

[5] Yan, J.B., Liew, J.Y.R., Zhang, M.H., Sohel, K.M., "Experimental and analytical study on ultimate strength behaviour of steel-concrete-steel sandwich composite beam structures", Materials and Structures, 48(5), 1523-1544, 2015. https://doi.org/10.1617/s11527-014-0252-

[6] Dai, X.X. and Liew, J.Y.R., "Fatigue performance of light-weight steel-concrete-steel sandwich systems", Journal of Constructional Steel Research, 66(2), 256-276, 2010 https://doi.org/10.1016/j.jcsr.2009.07.009.

[7] Yan, J.B., Wang, Z., Luo, Y.B., Wang, T., "Compressive behaviours of novel SCS sandwich composite walls with normal weight concrete", Thin-Walled Structures, 141, 119-132, 2019. https://doi.org/10.1016/j.tws.2019.01.051

[8] Yan, J.B., Wang, Z. and Wang, T., "Compressive behaviours of steel-concrete-steel sandwich walls with J-hook at low temperatures", Construction and Building Materials, 207, 108-121, 2019. https://doi.org/10.1016/j.conbuildmat.2019.02.116.

[9] Yan, J.B., Wang, Z. and Xie, J., "Compressive behaviours of double skin composite walls at low temperatures relevant to the arctic environment", Thin-Walled Structures, 140, 294-303, 2019. https://doi.org/10.1016/j.tws.2019.03.047.

[10] Mirza, O. and Uy, B., "Effects of the combination of axial and shear loading on the behaviour of headed stud steel anchors", Engineering. Structures, 32(1), 93-105, 2010. https://doi.org/10.1016/j.engstruct.2009.08.019.

[11] Guezouli, S. and Lachal, A., "Numerical analysis of frictional contact effects in push-out

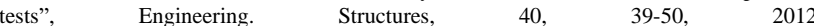
https://doi.org/10.1016/j.engstruct.2012.02.025.

[12] Qureshi, J., Lam, D. and Ye, J.Q., "Effect of shear connector spacing and layout on the shear connector capacity in composite beams", Journal of Constructional Steel Research, 67, 706719, 2011. https://doi.org/10.1016/j.jcsr.2010.11.009.

[13] Pavlovic, M., Markovic, Z., Veljkovic, M., Budevac, D., "Bolted shear connectors vs. headed studs behaviour in push-out tests", Journal of Constructional Steel Research, 88 , 134-149, 2013. https://doi.org/10.1016/j.jcsr.2013.05.003.

[14] Nguyen, H.T. and Kim, S.E., "Finite element modelling of push-out tests for large stud shear connectors", Journal of Constructional Steel Research, 65(10-11), 1909-1920, 2009. https://doi.org/10.1016/j.jcsr.2009.06.010.

[15] Shanmugam, N.E., Kumar, G. and Thevendran, V., "Finite element modeling of double skin composite slabs", Finite Elements in Analysis and Design, 38(7), 579-599, 2002. https://doi.org/10.1016/S0168-874X(01)00093-2.

[16] Yan, J.B., "Finite element analysis on ultimate strength behaviour of steel-concrete-steel 
sandwich composite beam structures", Materials and Structures, 48(6), 1645-1667, 2015. https://doi.org/10.1617/s11527-014-0261-3.

[17] Yan, J.B., Liew, J.Y.R., Zhang, M.H., "Shear-tension interaction strength of J-hook connectors in steel-concrete-steel sandwich structure", Advanced Steel Construction, 11(1), 72-93, 2015.

[18] Yan, J.B., Wang, Z., Wang, X., "Behaviour of steel-concrete-steel sandwich plate under different ice-contact pressure", Advanced Steel Construction, 15(1), 116-122, 2019. https://doi.org/10.18057/IJASC.2019.15.1.15.

[19] Qi, Y., Gu, Q., Sun, G.H., Zhao, B.C., Wang, H.F., "Tensile force and bending moment demands on headed stud for the design of composite steel plate shear wall", Advanced Steel Construction, 15(4), 338-348, 2019. https://doi.org/10.18057/IJASC.2019.15.4.5.

[20] Li, Y. and Hu, H.S., "Finite element analysis of local buckling behaviour of steel plates in concrete-filled double steel plate composite shear walls", Journal of Building Structures, 38 $112-117,2017$

[21] Fan, J.S., Zhu, Y.Y., Cui B., Huang, L.J., Spencer, B.F., "Experimental and numerical investigations on large-scale concrete-filled double-steel-plate composite structures", Engineering Structures, 231, 2021. https://doi.org/10.1016/j.engstruct.2020.111749.

[22] Vecchio, F.J. and McQuade, I, "Towards improved modeling of steel-concrete composite wall elements", Nuclear Engineering and Design, 241(8), 2629-2642, 2011. https://doi.org/10.1016/j.nucengdes.2011.04.006

[23] Choi, B.J. and Han, H.S., "An experiment on compressive profile of the unstiffened steel plate-concrete structures under compression loading", Steel and Composite Structures, 9(6), 519-534, 2009. https://doi.org/10.12989/scs.2009.9.6.519.

[24] Zhang, K., Varma, A.H., Malushte, S.R., Gallocher, S., "Effect of shear connectors on local buckling and composite action in steel concrete composite walls", Nuclear Engineering and Design, 269(4), 231-239, 2014. https://doi.org/10.1016/j.nucengdes.2013.08.035.

[25] Yang, Y., Liu, J.B. and Fan, J.S., "Buckling behavior of double-skin composite walls: An experimental and modeling study", Journal of Constructional Steel Research, 121, 126-135, 2016. https://doi.org/10.1016/j.jcsr.2016.01.019

[26] Liang, Q.Q. and Uy, B., "Theoretical study on the post-local buckling of steel plates in concrete-filled box columns", Computers and Structures, 75(5), 479-490, 2000. https://doi.org/10.1016/S0045-7949(99)00104-2.

[27] Yan, J.B., Wang, X.T. and Wang, T., "Compressive behavior of normal weight concrete confined by the steel face plates in SCS sandwich wall", Construction and Building Materials, 171, 437-454, 2018. https://doi.org/10.1016/j.conbuildmat.2018.03.143.

[28] Yan, J.B., Chen, A.Z., Wang, T., "Compressive behaviours of steel- UHPC-steel sandwich composite walls using novel EC connectors", Journal of Constructional Steel Research, 173, 2020. https://doi.org/10.1016/j.jcsr.2020.106244.

[29] Yan, J.B., Chen, A.Z., Wang, T., "Axial compressive behaviours of steel-concrete-steel sandwich composite walls with novel enhanced C-channels", Structures, 28, 407-423, 2020. https://doi.org/10.1016/j.istruc.2020.08.070.

[30] ABAQUS standard user's manual, version 6.14, Providence, RI(USA): Dassault Systems Corp, 2012.

[31] Xie, J., Li, X. and Wu, H., "Experimental studies on the axial-compression performance of concrete at cryogenic temperatures", Construction and Building Materials, 72, 380-388, 2014. https://doi.org/10.1016/j.conbuildmat.2014.09.033.

[32] Hibbitt, H.D., Karlson, B.I. and Sorensen, E.P., "ABAQUS/standard user's manual. Version 6.9", Hibbitt, Karlsson, \& Sorensen, Inc, 2009.

[33] CEB-FIP, CEB-FIP model code 1990, Trowbridge, Wiltshire, UK: Comite' EuroInternational Du Be 'ton, Redwood Books, 1993.

[34] Yan, J.B., Xiong, M.X., Qian, X.D., Liew, J.Y.R., "Numerical and parametric study of curved steel-concrete-steel sandwich composite beams under concentrated loading", Materials and Structures, 49, 3981-4001, 2016. https://doi.org/10.1617/s11527-015-0768-2.

[35] Yan, J.B., "Ultimate strength behavior of steel-concrete-steel sandwich composite beams and shells", PhD thesis, National University of Singapore, Singapore, 2012.

[36] BS EN 1994-1, "Eurocode 4: Design of Composite Steel and Concrete Structures: Part 1.1 General Rules and Rules for Buildings", British Standards Institution, London, 1999.

[37] AISC, ANSI/AISC 360-10, "Specification for Structural Steel Buildings", American Institute of Steel Construction, Chicago, II, 2010.

[38] GB5011-2010, "Code for seismic design of buildings", Beijing, China Standards Press, 2010 